\title{
El sitio arqueológico Cinacantan. Primer levantamiento indígena en Cuscatlán
}

\author{
Francisco Roberto Gallardo Mejía \\ Arqueólogo \\ Secretaría de Cultura de la Presidencia \\ Academia Salvadoreña de la Historia
}

Sin duda alguna, la conquista del peñol de Zinacantán por los españoles marcó el paroxismo de la resistencia de los denodados guerreros cuzcatlecos (Lardé y Larín, 2000).

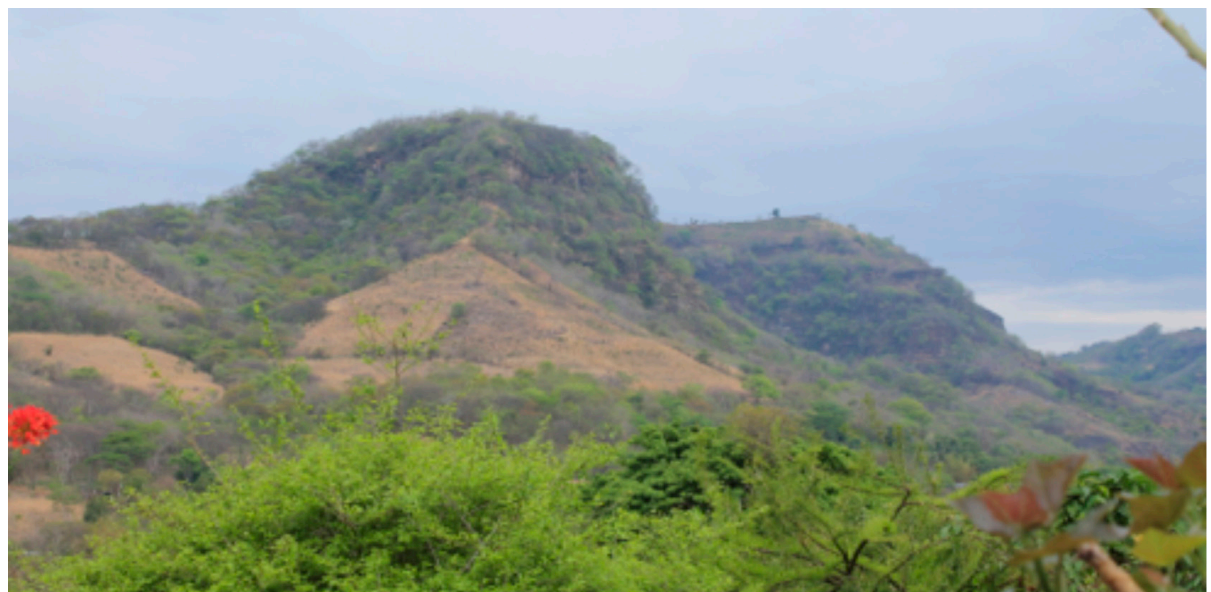

\section{Introducción}

Cinacantan es uno de los sitios arqueológicos históricos más importantes y representativos en El Salvador. Su relevancia no solamente radica en que aquí ocurrió una de las batallas mejor documentadas entre españoles y nativos en nuestro territorio, sino también en que este acontecimiento puede considerarse como el primer levantamiento indígena en Cuscatlán. El lugar exacto donde ocurrió esta batalla fue olvidado y se mantuvo desconocido para los investigadores hasta que fue identificado en el año 1999 en un peñón sobre la cordillera del Bálsamo, municipio de Tamanique. Tal y como lo afirma Lardé y Larín (2000), conocer la ubicación exacta del antiguo pueblo y fortaleza de Cinacantan es de vital interés en la reconstrucción histórica y los orígenes de la nacionalidad salvadoreña. 
El sitio consiste en una formación rocosa arqueológicamente registrada como el peñón de Cinacantan y cartográficamente conocida como cerro Redondo, siendo este el lugar donde se agruparon varios pueblos pipiles que se defendieron contra el Ejército español comandado por Diego de Alvarado, primo del Adelantado Pedro de Alvarado. Los rasgos arqueológicos se extienden por tres kilómetros hacia el noroeste donde se encuentran grupos arquitectónicos ubicados en las planicies sobre las mesetas. Hasta la fecha se han identificado seis sectores con un total de 44 estructuras, aunque se evidencian muchas fundaciones que probablemente fueron parte de edificios domésticos y que no se incluyeron en el mapa que aparece en este estudio, por lo que en esta área podría haber más de cien estructuras arqueológicas. Hasta la fecha de elaborar este documento, Cinacantan es el sitio más extenso que se ha registrado en la cordillera del Bálsamo.

Este lugar no solamente es importante por su historia y relevancia arqueológica, sino también por el potencial turístico que presenta. La imponente ubicación en las mesetas sobre la cordillera hace de Cinacantan un sitio especial desde donde se aprecia el entorno montañoso y hacia el sur el océano Pacífico. La constante y creciente afluencia turística en la zona, especialmente a las playas cercanas como La Libertad, El Tunco y El Zonte, hacen que este sitio arqueológico deba convertirse en un futuro parque arqueológico singular, entre otros lugares del país, y de esta forma atraer a visitantes y expandir la actividad económica desde la costa hacia las montañas en el interior.

Cinacantan debe ser investigado, pero también protegido. Actualmente los terrenos donde se encuentran los rasgos culturales pertenecen a varios propietarios privados. Es necesario delimitar el área donde se encuentran los vestigios arqueológicos e iniciar gestiones para que sea adquirido y garantizar su protección, especialmente ahora que muchos empresarios con negocios en la playa están comprando terrenos en la cordillera del Bálsamo para desarrollarlos, por lo que futuros proyectos pueden afectar negativamente el lugar.

A pesar de la poca investigación realizada en este sitio, su importancia es sobresaliente y se convierte en un lugar único en nuestro país, ya que simboliza la resistencia indígena y la implacabilidad española para imponer el nuevo orden occidental. La derrota cuscatleca en Cinacantan es uno de los marcadores en la dominación española en el territorio que ahora es El Salvador.

\section{Ubicación}

El sitio arqueológico Cinacantan se ubica en la cordillera del Bálsamo, a unos $5 \mathrm{~km}$ al sur de Tamanique, departamento de La Libertad, a una altura promedio de $460 \mathrm{msnm}$. (figuras 1 y 2). Las coordenadas del cerro Redondo, o peñón de Cinacantan, al extremo sur del sitio son: $13^{\circ} 32$ '29.83’N $8^{\circ} 9^{\circ} 23$ '30.55'O. Los restos arquitectónicos se extienden sobre las mesetas entre los lugares actualmente conocidos como cerro Redondo, Pueblo Viejo y Tarpeya. Para llegar al sitio se toma la carretera del litoral hacia el oeste del puerto de La Libertad, y en el kilómetro 43 se toma la calle pavimentada hacia el norte que se dirige al pueblo de Tamanique. Después de unos $6 \mathrm{~km}$, se puede ver el cerro Redondo al oeste de la calle pavimentada. El acceso es posible caminando desde la calle 
pavimentada o por vehículo, tomando el desvío hacia el oeste cerca del caserío Tarpeya. Las estructuras prehispánicas se encuentran en grupos separados, extendiéndose en un área de $3 \mathrm{~km}$ hacia el noroeste del cerro Redondo hasta el norte del cantón y caserío Tarpeya. Estos grupos arquitectónicos han sido denominados como sectores, ya que se considera que todos forman parte del mismo sitio.

\section{Identificación y registro del sitio}

La identificación de este sitio arqueológico como el lugar donde ocurrió el levantamiento indígena mencionado en los documentos históricos era punto de debate entre varios investigadores; y coincido con Lardé y Larín cuando dice: "La ubicación exacta del antiguo pueblo y fortaleza de Zinacantán o 'la ciudad del murciélago'..., es de vital interés en la reconstrucción del proceso de la conquista española y orígenes de la nacionalidad salvadoreña" (Lardé y Larín, 2000:110). El mismo autor se apoya en los documentos históricos (Relación Marroquín 1532) donde se incluyen los pueblos de encomienda que entregaban tributo a los vecinos de la villa de San Salvador, determinando así la ubicación "por la Costa del Bálsamo" y llegando a la conclusión de que el sitio se encuentra a $6 \mathrm{~km}$ al suroeste de Chiltiupán, en la circunscripción del caserío Sinaca (Ibid). Evidentemente, Lardé y Larín se basa en el topónimo del caserío para relacionar Sinaca con Cinacantan.

Amaroli (1991) determina que el pueblo de Zuacanclán, que aparece en la Relación Marroquín, es el mismo que Cinacantan; y también menciona acertadamente que Cinacantan se ubica en la cordillera del Bálsamo, más específicamente "en una zona en los alrededores del puerto de La Libertad, en el extremo oriente de la Costa del Bálsamo" (Amaroli, 1991:69). Este autor se basa en las distancias presentadas en leguas

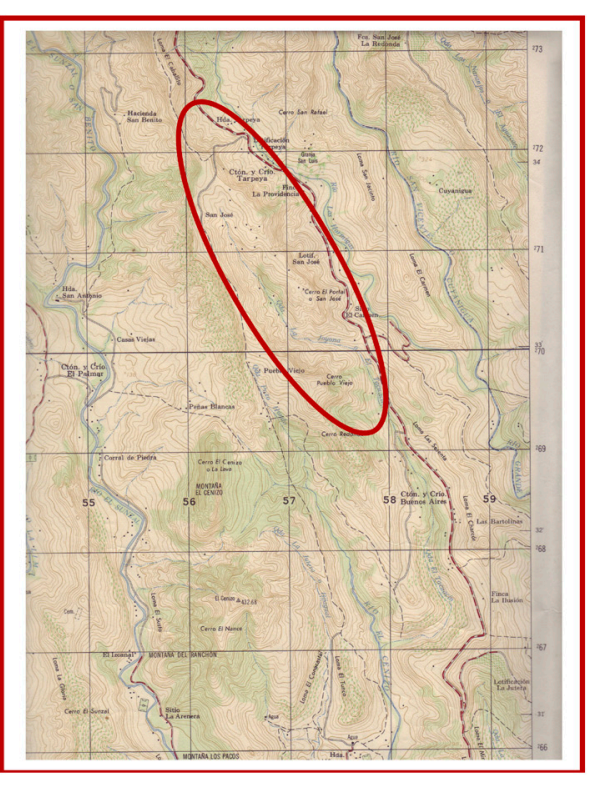

Figura 1. Ubicación del sitio Cinacantan, dentro del óvalo que aparecen en la Relación Marroquín y en las descripciones del lugar en el mismo documento.

En el año de 1999, en base al conocimiento que algunas personas en Tamanique todavía llaman "Cinacantan" al lugar donde se encuentra el cerro Redondo, los investigadores Fowler, Gallardo y Hamilton realizamos una visita al sitio, observando dos grupos de estructuras e identificando el cerro Redondo como el peñol donde ocurrió el levantamiento indígena mencionado en los documentos (Gallardo, 2010:110). Posteriormente, en el año 2000 el autor realizó cinco visitas al sitio, elaborando el mapa que aparece en este documento.

En octubre de 2005, el autor presentó la ponencia titulada: "El peñón de 
Cinacantan: primer levantamiento indígena en El Salvador", durante el Primer Congreso Centroamericano de Arqueología en el Museo Nacional de Antropología Dr. David J. Guzmán. Posteriormente, a finales del mismo año, se dio a conocer el sitio en una breve publicación en la revista Fiestas Patronales de Tamanique, donde se describe y explica el sitio arqueológico Cinacantan como el lugar donde ocurrió el levantamiento indígena (Gallardo, 2005), presentándose después esta información a la gente de Tamanique durante sus fiestas patronales.

Cinacantan es incluido por Erquicia (2008), en su documento titulado "Proyecto de registro y reconocimiento de sitios arqueológicos históricos de El Salvador", identificando este sitio como el lugar donde ocurrió el levantamiento indígena. En este documento también se menciona que el levantamiento indígena ocurrió en 1538 (Ibid:24), una fecha incorrecta, ya que la batalla se dio poco tiempo después de haberse fundado la villa de San Salvador en 1528 (Ministerio de Educación, 1994:81); y el territorio de Cuscatlán ya tenía varios años de haber sido pacificado para 1538.

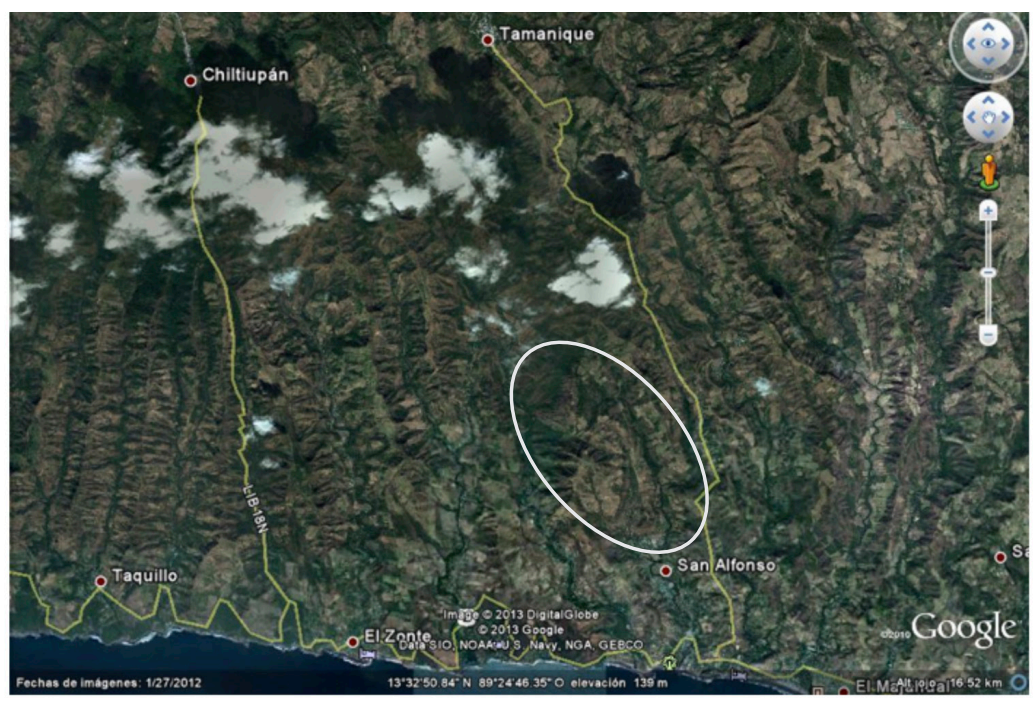

Figura 2. Ubicación de sitio Cinacantan, dentro del óvalo.

\section{La cordillera del Bálsamo}

El sitio arqueológico Cinacantan se encuentra en la cordillera del Bálsamo. Esta región de El Salvador se llama así por la resina que se extrae del árbol del mismo nombre (Myroxilon balsamun). Desde tiempos prehispánicos, este producto se usaba para fines curativos y era comercializado extensamente. Durante la época colonial española la resina y corteza del bálsamo eran exportadas al Perú y posteriormente a otros lugares, incluyendo Europa. Aunque todo el bálsamo se producía en la cordillera salvadoreña, este producto llegó a conocerse como "bálsamo del Perú", ya que era en este lugar suramericano donde se almacenaba antes de llegar a su destino final. 
La cordillera del Bálsamo es parte de una formación geológica que inicia a unos $12 \mathrm{~km}$ al este de Punta Remedios y va hacia el oriente, pasando al sur de San Salvador, hasta el volcán de San Vicente, desapareciendo en el valle del río Jiboa. La cresta principal o “cumbre" está en el norte, orientada este-oeste; y en ese lado hace un abrupto declive hacia el norte hasta la "Fosa Zapotitán-Olomega", denominada así por Williams y Meyer-Abich (1955). El declive hacia el sur es menos drástico, llegando hasta el océano Pacífico en Sonsonate y La Libertad. La altura máxima se encuentra en la cumbre, al sur de Jayaque, con 1.500 msnm. Desde Santa Tecla, hay accesos que comunican los pueblos de Cuisnahuat, Ishuatan, Teotepeque, Chiltiupán y Tamanique, hasta llegar a la costa.

Gierloff-Emden (1976) divide esta cordillera en un sector oriental y otro occidental. El sector occidental inicia al este de Punta Remedios y termina en la playa San Blas, en el departamento de La Libertad. El municipio de Tamanique se ubica en la parte sureste del sector occidental. Las tierras que constituyen la cordillera son tobas andesíticas, brechas, lavas, rocas de filón y tobas fundidas cuyos espesores oscilan entre 30 y 300 $\mathrm{m}$. Estas confirman la actividad tectónica que todavía predomina en la región (Ibid).

Estudios geológicos recientes (Lexa et al., 2011) han determinado que esta cordillera (Formación Bálsamo) se formó por la actividad de dos grandes estrato-volcanes basálticos-andesíticos hasta andesíticos: Panchimalco y Jayaque. Consisten en zonas con facies que van desde flujos de lava y brechas epiclásticas volcánicas gruesas de la zona proximal, brechas epiclásticas volcánicas/conglomerados de la zona media hasta los conglomerados volcánicos epiclásticos y areniscas de la zona distal. La región donde se encuentra Tamanique se formó con la formación del estrato-volcán de Jayaque hace aproximadamente 1.5 y 2.6 millones de años, y se compone de lavas andesíticas, tobas y brechas/conglomerados, representando los restos del estrato-volcán. La caldera de este rasgo se conoce como la Formación Cuscatlán (Ibid).

Los cultivos principales en esta zona son maíz y frijol como sustento básico para la mayoría de la población, aunque también se cultivan hortalizas y frutas. En las partes altas se cultiva café que, en el mejor de los casos, es exportado. Algunas familias se dedican a la crianza de ganado porcino y aves de corral. La crianza de ganado vacuno ocurre en menor cantidad. Recientemente, algunas playas en la costa de esta cordillera se han convertido en polos turísticos debido a la calidad de olas para practicar el surf. Las formaciones rocosas que llegan hasta la playa y a veces entran al mar, así como los ríos que desembocan en esta parte del Pacífico, han formado "puntas" de piedras que generan algunas de las mejores olas en el mundo para practicar este deporte.

Uno de los problemas ambientales más graves que sufre la cordillera del Bálsamo actualmente es la tala de sus bosques para sembrar maíz y frijol, usando el método milenario de roza y quema. Cada año se pueden apreciar grandes áreas completamente deforestadas que no habían sido intervenidas anteriormente. La topografía agreste y la naturaleza rocosa del suelo hacen que la erosión lave la capa de tierra fértil y que termine en las quebradas y riachuelos hasta llegar al mar. Este fenómeno puede apreciarse todos los inviernos cuando el agua del mar cambia de color debido a la cantidad de 
sedimentos depositados por los ríos. Otro problema grave es el crecimiento turístico, que con el tiempo no será ambientalmente sostenible. La cantidad de turistas, así como la construcción de hoteles y diferentes tipos de negocios en playas como El Tunco y El Zonte, están contaminando considerablemente el medioambiente sin medidas de regulación. Esto incluye desechos sólidos y la contaminación de los mantos acuíferos.

\section{Investigaciones anteriores y antecedentes históricos}

La cordillera del Bálsamo ofrece un gran potencial arqueológico. Debido a su ubicación y geografía es una región que presenta sitios con un alto grado de preservación y que no han sido dañados por actividades antrópicas. Hasta la fecha, la Dirección de Arqueología de la Secretaría de Cultura tiene registrados 25 sitios arqueológicos ubicados dentro de la cordillera (Escamilla, 2011). A continuación se incluye un listado de antecedentes históricos y las investigaciones realizadas en la zona, que incluye la parte occidental de la cordillera del Bálsamo.

- En 1522, el navegante español Andrés Niño viaja por mar frente a la costa del Bálsamo y la llama "la del rostro fragoso". Esta es la primera incursión española al territorio.

- En 1853, el periodista y arqueólogo-etnólogo Ephraim George Squier llegó a El Salvador motivado por su interés en las migraciones pipiles. Squier hizo observaciones etnográficas y documentó un vocabulario náhuatl en Chiltiupán, departamento de La Libertad, publicando esta investigación en The States of Central America (1858). La llegada de este personaje al país es considerada como el nacimiento de la arqueología salvadoreña (Fowler, 1995).

- Entre 1863 y 1869, el viajero alemán Simeón Habel recorrió el sector occidental de la cordillera del Bálsamo, llegando hasta Sonsonate.

- En 1973, el arqueólogo Luis Casasola excavó varios pozos de sondeo en Jayaque (Cobos, 1994).

- En 1989 William Fowler realiza investigaciones en el Cerro de Ulata como parte del Proyecto Izalco (Fowler, 1989).

- En el año 1999, Fowler, Hamilton y Gallardo registran el sitio de Cinacantan y determinan que este fue el lugar donde ocurrió el levantamiento indígena. En junio de ese año, Gallardo realiza cinco visitas al sitio y elabora un mapa de Cinacantan con brújula y cinta métrica (presentado en este documento).

- El mismo año de 1999, Marlon Escamilla registra y documenta el sitio Piedra Herrada en el municipio de Comasagua, departamento de La Libertad (Escamilla, 1999).

- En 2001, Hamilton realiza un mapa que incluye tres sectores con estructuras arqueológicas del sitio Cinacantan, municipio de Tamanique (Hamilton, 2002).

- En 2005 y 2006, el arqueólogo Zachary Revene realiza un estudio sobre la producción de bálsamo en Atiluya, departamento de Sonsonate (Revene, 2007).

- En 2007, Méndez (2007) realiza un recorrido en un área de 400 manzanas en la Cooperativa San Isidro, registrando cuatro sitios arqueológicos. Hasta la fecha, Méndez ha registrado nuevos sitios y continúa su investigación en la zona.

- En el año 2010, Marlon Escamilla inicia su investigación en la cordillera del Bálsamo con el objetivo de registrar nuevos sitios y conocer más sobre las migraciones nahuas en la región. Las investigaciones de Escamilla continúan hasta la fecha. 


\section{Descripción del sitio}

Según los documentos históricos, en la época prehispánica este asentamiento era conocido como Cinacantan o "la ciudad de los murciélagos", ya que proviene de cinacan, "murciélago", y el sufijo locativo tan, “en”, "ciudad” (Larde y Larín, 2000). También puede considerarse la versión de "lugar del murciélago" (Amaroli, 1991). Todavía es posible encontrar personas de edad que conocen el sitio por su antiguo nombre; y fue así como se logró relacionar este lugar con el importante acontecimiento histórico.

El sitio fue registrado por Fowler, Hamilton y Gallardo el 14 de junio de 1999. Ese mismo mes, Gallardo realizó cinco visitas en compañía de Adonai Cardoza con el objetivo de elaborar el mapa que aparece en este documento. Este mapeo se realizó con una brújula Suunto y una cinta métrica, logrando ubicar seis sectores (figura 3) orientados hacia el noroeste del cerro Redondo. Cada sector comprende una agrupación de estructuras, y los seis sectores conforman un total de 44 estructuras consistentes principalmente en montículos, plataformas y terrazas. En el año 2002, Conard Hamilton realizó un mapa con estación total de tres agrupaciones de montículos (sectores 1, 2 y 3), ubicando 23 estructuras (Hamilton, 2002).

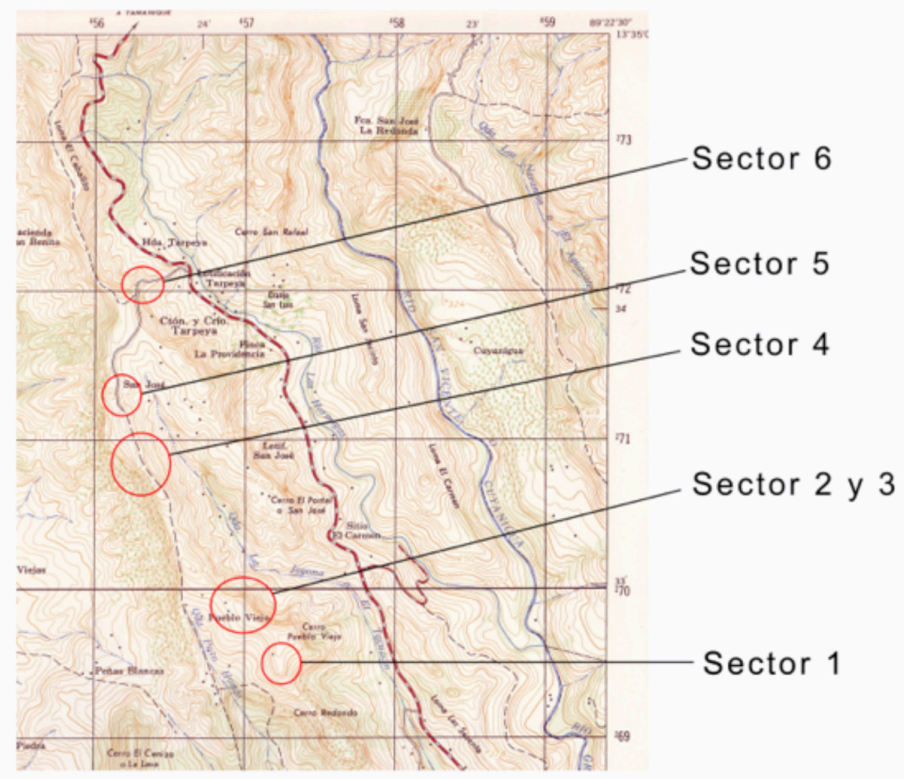

Figura 3. Agrupaciones de estructuras denominados sectores.

El mapa que aparece en este documento fue elaborado por Gallardo en 1999; y el posterior trabajo de Hamilton (2002) se tomó como referencia para incluir los tres sectores mapeados. Es necesario mencionar que el mapeo con brújula y cinta métrica presenta limitantes, especialmente en lugares agrestes con topografía dificultosa característica de Cinacantan, por lo que se recomienda realizar un mapa con estación total, que seguramente corregirá errores al presente trabajo. También es importante 
aclarar que el límite norte del sitio se determinó por una pendiente abrupta y no por un recorrido del área, por lo que existe probabilidad en la presencia de rasgos culturales al norte del sector 6 .

A continuación se describen cada uno de los sectores del sitio con su respectivo mapa:

\section{A. Sector 1 (figura 4)}

El sector 1 se ubica justamente al noroeste de la formación como alfarda que conecta este sitio con el cerro Redondo, lugar donde acometieron los españoles para tomar el peñol, según el relato de Peñacorba (Barón Castro, 1996). Esta es la agrupación de estructuras más cerca al peñol, y está orientada entre 330 y 350 grados al oeste del norte. El datum de este sector se ubicó sobre la estructura 1 con lat. 13³2'40.84" y long. 89²3'42.34" (Hamilton, 2002). Este sector consiste en siete estructuras agrupadas, seis de las cuales forman una plaza principal abierta hacia el lado oeste. Las estructuras de mayor tamaño se ubican al norte, sur y este (estructuras 1, 2, 4 y 6), dejando el espacio abierto al oeste. Hay dos estructuras pequeñas (estructuras 3 y 5) en el centro de la plaza y frente a las estructuras grandes ubicadas al este. Todas las construcciones siguen la misma orientación adaptada a la meseta, excepto la estructura 1, que está orientada 16 grados al oeste del norte. La estructura 7, en el extremo norte de este sector, está fuera de la plaza principal.

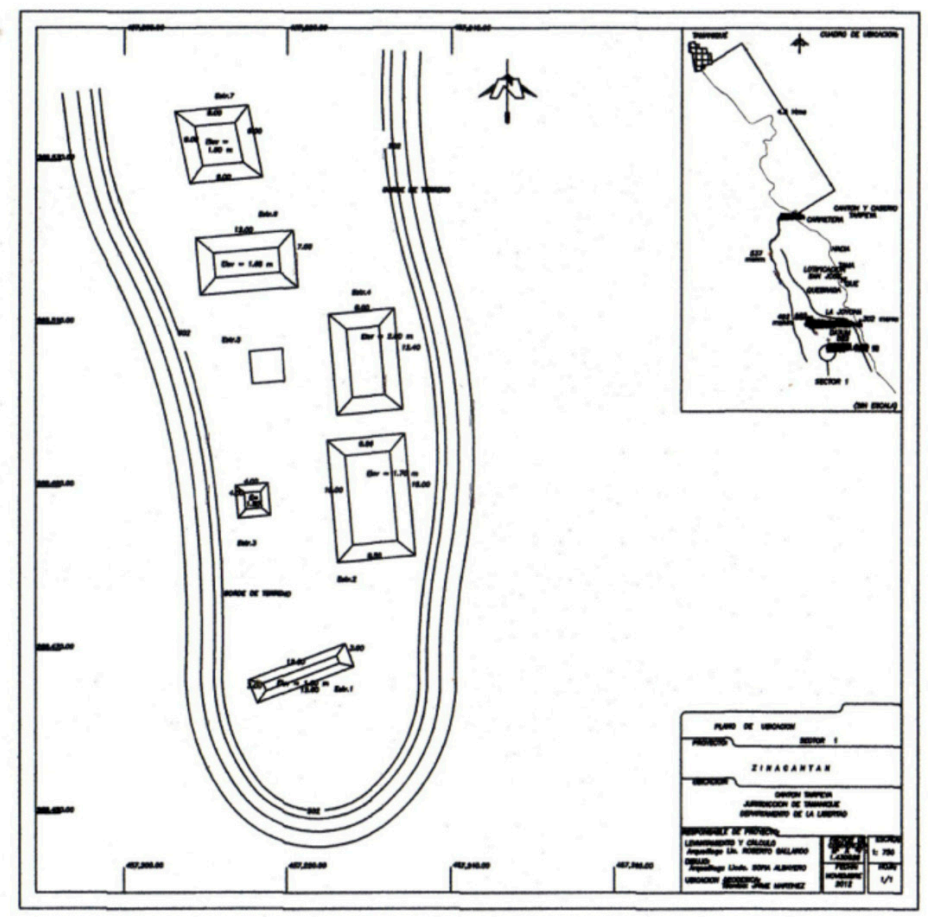

Figura 4. Sector 1. Mapa de Gallardo y Albayero. 


\section{B. Sector 2 (figuras 5 y 7 ).}

Este sector consiste de diez estructuras y se encuentra en una meseta larga orientada noroeste-sureste a una distancia aproximada de $300 \mathrm{~m}$ al noroeste del sector 1 , y a un kilómetro de cerro Redondo, con orientación promedio de 144 grados hacia el sur. El datum se ubica en la estructura 1, cerca del centro del sector con latitud norte $13^{\circ} 32^{\prime} 53.28^{\prime \prime}$ y longitud oeste de 89²3'50.6" (Ibid). La orientación de este sector es generalmente 38 grados al oeste del norte, y las estructuras siguen esta orientación o se encuentran perpendiculares 52 grados al este del norte. Seis estructuras (Estr. 1, $3,4,5,7,9)$ forman una plaza principal abierta hacia el oeste con las estructuras de mayor tamaño al norte, este y sur. Al extremo norte del sector se encuentra una agrupación de estructuras afueras de la plaza (estructuras 2, 10,6 y 8).

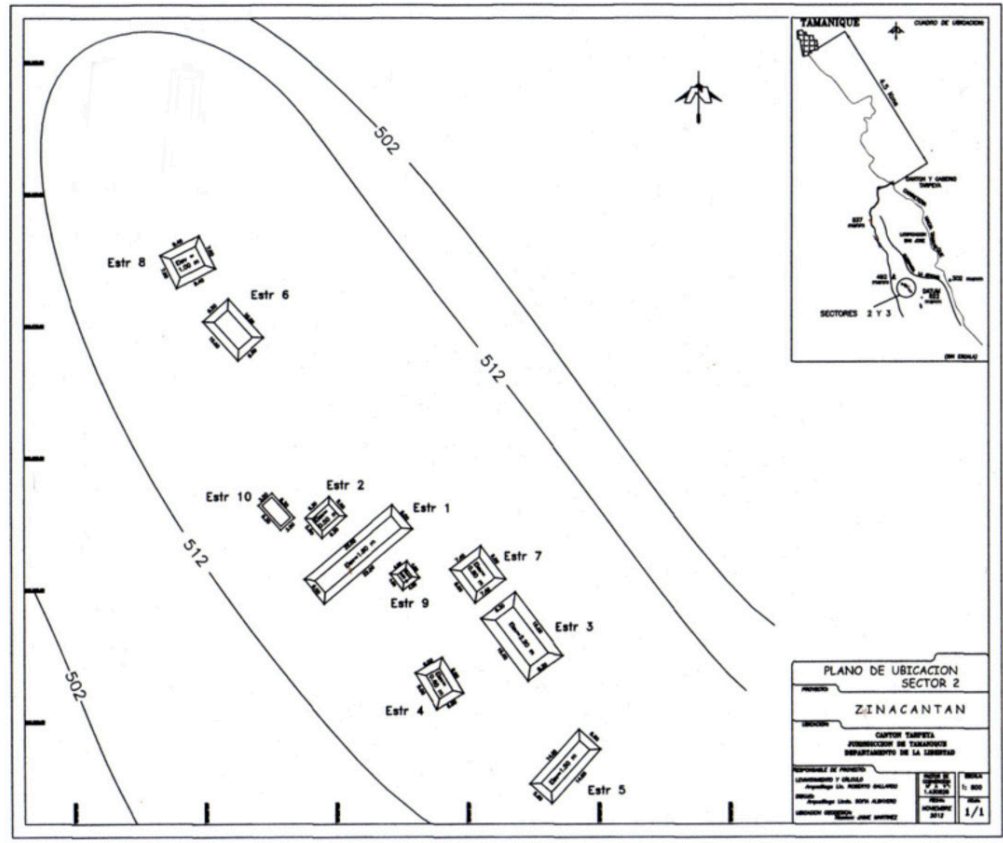

\section{Sector 3 (figuras 6 y 7 )}

El sector 3 se encuentra apenas a unos $30 \mathrm{~m}$ al norte del sector 2; sin embargo, hay una pendiente inclinada hacia el noroeste que separa los dos grupos de montículos. Este sector consiste de ocho estructuras, la mayoría ordenadas noroeste-sureste. Seis de las ocho estructuras se encuentran alineadas en el lado este del sector, formando un espacio abierto al oeste, similar a los sectores 1 y 2 , aunque considero que este caso no puede definirse como una plaza. 


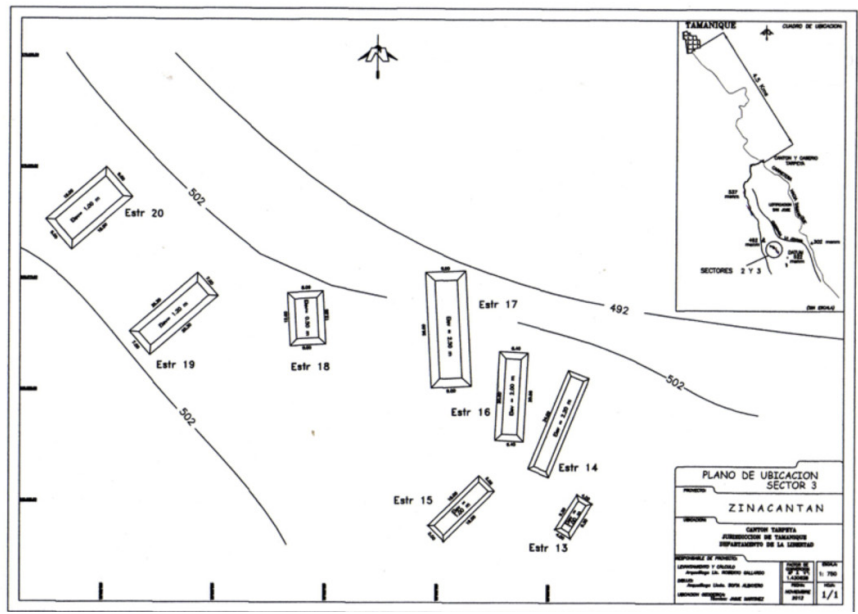

Figura 6. Sector 3. Mapa de Gallardo y Albayero.

El hecho que seis de las ocho estructuras son rectangulares y no forman una plaza formal sugiere que este sector tenía una función diferente a la de los sectores $1,2,4,5$ y 6 .

La estructura 17 ha sido dividida por una vereda, por lo que aparenta ser dos estructuras diferentes.

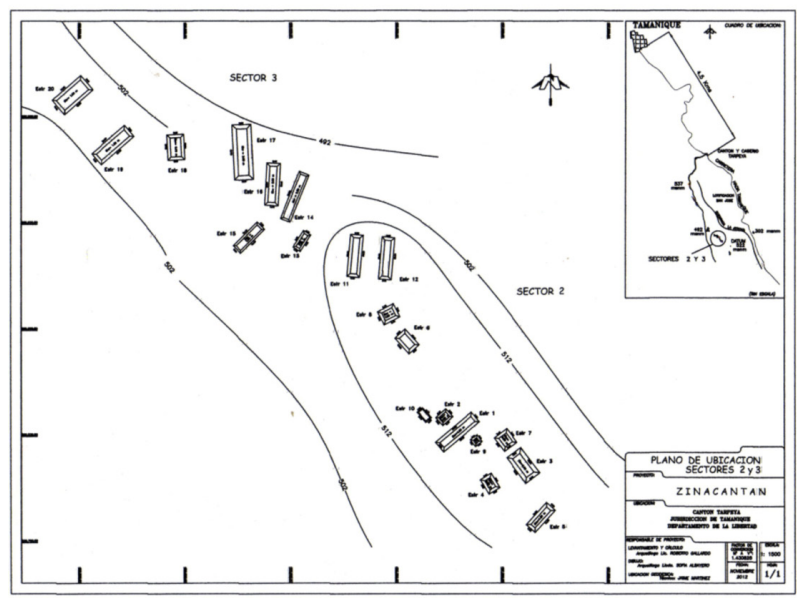

Figura 7. Sector 2 y 3 . Ambos sectores están separados por una inclinación hacia el noroeste. Mapa de Gallardo y Albayero.

\section{Sector 4 (figura 8)}

El sector 4 se encuentra a unos $900 \mathrm{~m}$ hacia el noroeste (328 grados) del sector 3 . Este lugar es llamado San José. Entre el sector 3 y el sector 4 se pudieron identificar 
varias plataformas pequeñas construidas generalmente con una línea de piedras, probablemente estructuras domésticas que no fueron incluidas en el mapa. Este espacio es muy accidentado donde predominan dos pequeñas formaciones naturales. Este sector consiste en once estructuras entre las que se encuentra una terraza bien definida entre las estructuras 6 y 12.

Las estructuras 1, 2 y 3 forman una plaza abierta en el lado oeste, igual a los sectores 1 y 2. La estructura 1 es la construcción más grande y separa la plaza con una alineación de estructuras que continúa hacia el noroeste y que dejan un espacio abierto al lado oeste sin estructuras.

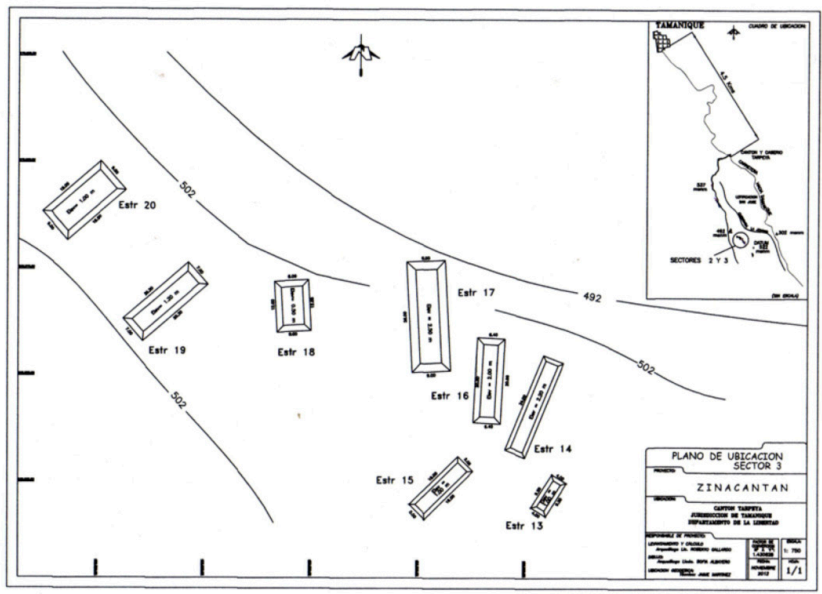

Figura 8. Sector 4. Mapa de Gallardo y Albayero.

\section{E. Sector 5 (figura 9)}

El sector 5 se ubica a unos 300 $\mathrm{m}$ hacia el noroeste del sector 4 , pasando una inclinación hacia el norte; y está localizado en otra meseta larga orientada norte-sur. Este sector consiste de cinco estructuras. Las estructuras 1, 2 y 3 forman una pequeña plaza también abierta en el lado oeste; y las estructuras 3, 4 y 5 también dejan un espacio abierto en el lado oeste. El lado este de la estructura 5 ha sido partido por una calle vecinal que corre norte-sur.

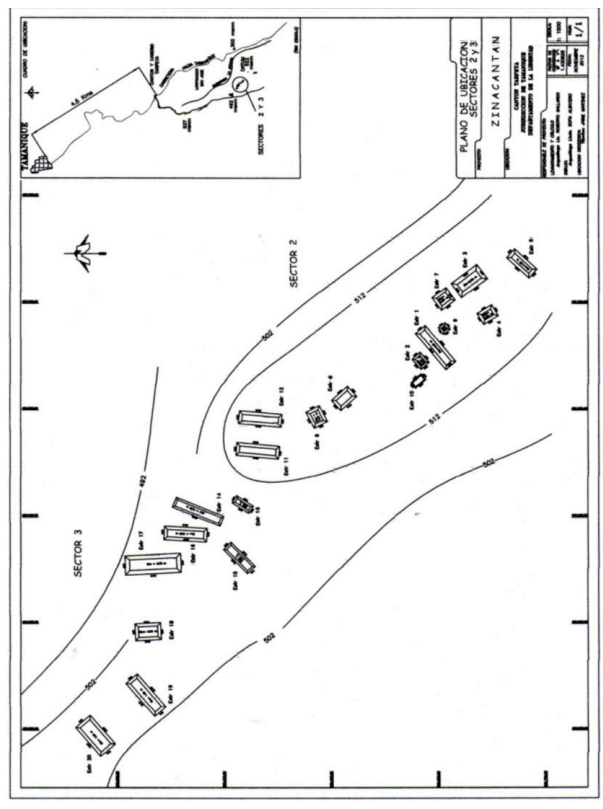

Figura 9. Sector 5. Mapa de Gallardo y Albayero. 


\section{F. Sector 6 (figura 10)}

Este sector es el último mapeado en esta temporada de 1999, y parece ser la última agrupación arquitectónica a más de $3 \mathrm{~km}$ hacia el noroeste del cerro Redondo. Consiste en tres estructuras, dos de ellas largas y el extremo noroeste de la estructura 3 ha sido cortado por una calle. Una visita posterior por el autor y David Messena el 30 de abril de 2013 confirmó aron la existencia de más estructuras en este sector.

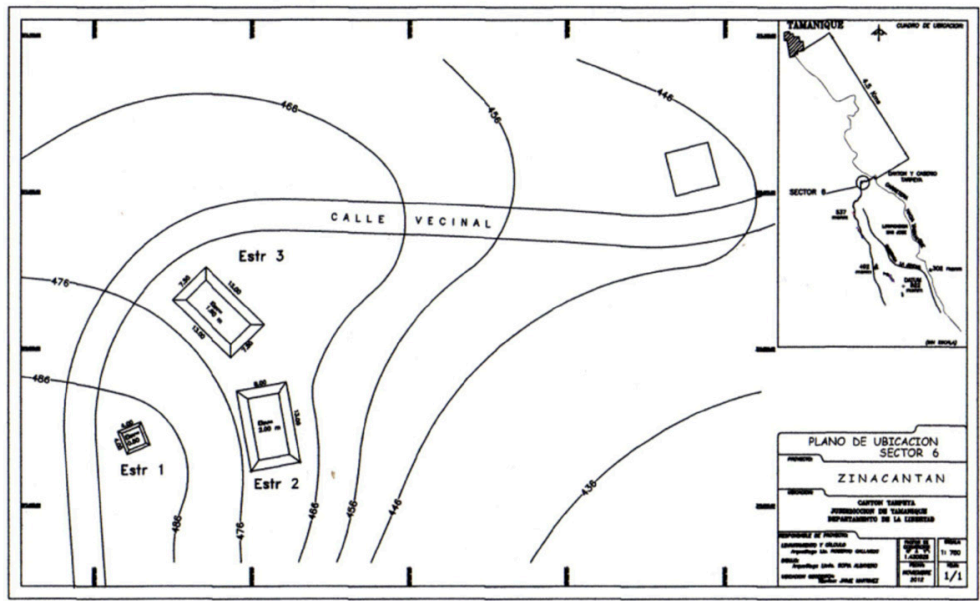

Figura 10. Sector 6. Mapa de Gallardo y Albayero.

\section{Conclusiones en base al mapeo}

El mapa presentado en este documento fue realizado por Gallardo en 1999; y el mapa de Hamilton (2002), quien mapeó los sectores 1, 2 y 4, fue usado como referencia comparativa. Hamilton designa estos sectores como sitios diferentes (sitios 1, 2 y 3 )., Sin embargo, en este documento se considera que todos los sectores forman un solo sitio. El sitio arqueológico Cinacantan es el más extenso y con la mayor cantidad de estructuras identificado hasta la fecha en la cordillera del Bálsamo. En el mapeo realizado en 1999 se identificaron seis sectores, con un total de 44 estructuras principales, también se

observó gran cantidad de plataformas, terrazas y estructuras pequeñas que indican que este sitio puede contener los restos de por lo menos unos cien edificios de diversos tamaños y funciones. Una característica presente que se encuentra en la mayoría de los sitios en esta región es que se aprovechó las mesetas planas sobre las formaciones rocosas para la edificación de conjuntos arquitectónicos. Tomando en consideración la estructura social de algunos grupos nahuas y, en este caso, de los pipiles (Fowler, 1981), la existencia de varios recintos ceremoniales separados sugieren la presencia de diferentes calpullis, o barrios familiares, que administraban cada uno. Los conjuntos de estructuras denominados como "sectores" en este documento se extienden por unos 3 $\mathrm{km}$ hacia el noroeste del cerro Redondo, punto donde se concentraron los indígenas para defenderse del ataque español. 
Todos los sectores están orientados noroeste-sureste y se conforman por estructuras consistentes en plataformas largas rectangulares, montículos cuadrados generalmente de mayor altura y estructuras pequeñas frente a estos, que algunos investigadores llamarían adoratorios. La mayoría de los sectores $(1,2,4$ y 5$)$ contienen estructuras que forman plazas pequeñas. Estas plazas generalmente se forman con las estructuras ubicadas en el borde de las mesetas en los lados norte, sur y este, formando un espacio abierto hacia el oeste, una característica en este sitio muy interesante que amerita estudios más profundos.

Hasta la fecha, los saqueos en el sitio han sido muy pocos y los montículos se encuentran en muy buen estado de conservación. La última visita al sitio antes de elaborar este documento fue realizada por el autor y David Messana el 30 de abril de 2013, constatando dos agujeros de saqueo en la estructura 2 del sector 4, algo que no existía en 1999 (figura 11). La mayoría de las estructuras muestran ser pirámides pequeñas construidas con piedras y tierra. Las estructuras principales se encuentran agrupadas en las mesetas sobre las formaciones montañosas comunes en la cordillera, aunque existen una considerable cantidad de plataformas pequeñas en las partes bajas que probablemente eran las casas de los agricultores y la clase baja. El patrón arquitectónico demuestra la forma en que los antiguos habitantes aprovecharon el escaso espacio en las planicies para ubicar las agrupaciones de estructuras más importantes. Esta ubicación habría proporcionado las siguientes ventajas:

Fácil comunicación con otros asentamientos en el área. Desde las mesetas en las partes altas del sitio se puede divisar un área geográfica bastante amplia que incluye el océano Pacifico hacia el sur, El Peñón de Comasagua hacia el noreste y el cerro El Cabro hacia el oeste. Esta ubicación habría facilitado la comunicación con asentamientos contemporáneos cercanos.

Ubicación defensiva. La ubicación de Cinacantan ofrece una defensa natural. Los grupos de estructuras se encuentran en mesetas rodeadas por inclinaciones y acantilados que hubieran dificultado un ataque enemigo. Esto fue comprobado en la época de la conquista cuando los españoles acometieron el peñol dos veces y fueron repelidos.

Control social. Los grupos elite del sitio habitaban en las mesetas donde se encuentran los recintos ceremoniales. Todas las inclinaciones y las partes bajas habrían sido aprovechadas para la agricultura. De esta forma la elite observaba desde las alturas las actividades del resto de la comunidad, estableciendo una estructura social muy efectiva que facilitaba a los gobernantes el control sobre el resto de la población.

Algunas desventajas sobre la ubicación de este sitio pudieron haber sido:

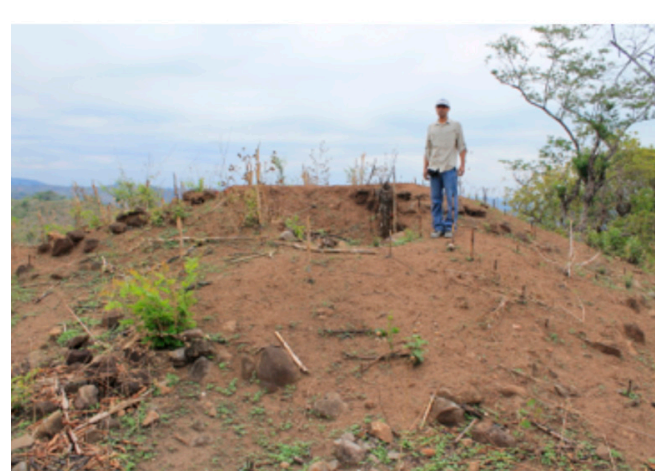

Figura 11. Agujero de saqueo en la estructura Estr. 2 del sector 4. 
Espacio limitado. Los núcleos arquitectónicos consistentes en su mayoría de estructuras ceremoniales se encuentran en las mesetas de las formaciones rocosas. Estas superficies ofrecen un espacio muy limitado y muchas veces angosto. La expansión de estructuras importantes era difícil debido a la falta de espacio, especialmente a medida que estos asentamientos se desarrollaban arquitectónicamente y su población aumentaba. La cercanía con otros sitios contemporáneos en un terreno con estas características geográficas se debió al aprovechamiento de la parte superior de las mesetas.

Difícil acceso a las fuentes de agua. La cordillera del Bálsamo se caracteriza por una geografía agreste y formaciones pétreas con mesetas en sus cúspides. Las áreas nucleares de muchos de los asentamientos en la cordillera se encontraban sobre estas mesetas; y las casas de habitación de los agricultores y la gente común parecen haber estado ubicadas en las faldas de estas formaciones rocosas. En esta región se encuentran riachuelos y quebradas que serpentean por el fondo de las barrancas, convirtiéndose en tributarios que alimentan algunos ríos que terminan desembocando en el océano Pacifico. En algunos casos, es posible encontrar nacimientos de agua en las partes altas, pero estos son escasos. El acceso al agua por los antiguos habitantes habría sido dificultosa y sin duda más problemático que en asentamientos ubicados en valles con ríos adyacentes, especialmente en tiempos de conflicto, ya que habrían tenido que dejar las partes altas defensivas para adquirir el vital líquido y transportarlo hasta las áreas pobladas.

Dificultad en la comunicación terrestre debido a la topografía agreste. Una de las razones por las cuales la cordillera del Bálsamo no ha sido objeto de desarrollo urbano y su riqueza arqueológica apenas se empieza a conocer es por su difícil acceso. La carretera del litoral fue finalizada hasta mediados de los años cincuenta, y el terreno agreste limitaba el contacto con las grandes poblaciones. Los antiguos habitantes debieron tener dificultades al trasladarse por tierra para llegar a otros asentamientos, y debió tomarles más tiempo trasladarse de un poblado a otro a pesar de las cortas distancias. Esto habría sido difícil y peligroso si un grupo enemigo tomaba control de los centros ceremoniales en las partes altas de las formaciones rocosas, ya que la visibilidad desde las cúspides habría facilitado la identificación de cualquier movimiento en las hondonadas y quebradas.

\section{El levantamiento indígena.}

Uno de los acontecimientos más importantes en la historia salvadoreña ocurrió en Cinacantan. Poco tiempo después de que los conquistadores españoles habían fundado la villa de San Salvador, en 1528, un grupo de pueblos indígenas se sublevó contra la invasión conquistadora y ocupó el peñol de Cinacantan (cerro Redondo) como foco de resistencia. En ese momento, San Salvador estaba ubicado al sur de Suchitoto en el valle de La Bermuda; y los restos son conocidos actualmente como el sitio arqueológico de Ciudad Vieja. La agrupación defensiva de pueblos indígenas hostiles en partes altas, como formaciones rocosas o el empeñolamiento, como lo llamaban los españoles, era 
una táctica defensiva común; y los documentos mencionan varios casos durante la Conquista. La sublevación indígena en Cinacantan tenía que ser sofocada, por lo que un contingente español fue enviado desde San Salvador hasta la cordillera del Bálsamo. El ejército punitivo era comandado por Diego de Alvarado y estaba formado por españoles e indios aliados. Esta batalla puede ser considerada el primer levantamiento indígena en la historia de Cuscatlán, puesto que sucedió cuando los españoles ya habían fundado un asentamiento formal y se consideraba que el establecimiento de una ciudad era el inicio en la imposición de una estructura social colonialista eurocéntrica. Al ser sofocado el levantamiento, se marca el final de la resistencia indígena en Cuscatlán e inicia el proceso de conquista paulatino, pero progresivo, que llegó a consolidarse pocos años después.

Este evento ha sido resumido en la obra El Salvador: descubrimiento, conquista y colonización de Jorge Lardé y Larín (2000), quien dedica tres breves capítulos a Cinacantan. Sin duda, la documentación más completa la proporciona Rodolfo Barón Castro en su obra Reseña Histórica de la Villa de San Salvador (1996), quien incluye un capítulo titulado El peñol de Cinacantlán. Amaroli (1991) también presenta información sobre este sitio y acontecimientos históricos basados en la Relación Marroquín. Posteriormente, la "Historia de El Salvador", Tomo I, incluye una breve sección sobre este sitio y la rebelión indígena (Ministerio de Educación, 1994).

La batalla de Cinacantan es la culminación de una serie de eventos que ocurren poco tiempo después de que se establece la villa de San Salvador en 1528. Los relatos más sobresalientes acerca del encuentro bélico fueron proporcionados por algunos testigos presenciales; pero Bartolomé Bermúdez y Miguel Díaz Peñacorba, quienes combatieron bajo el mando de Diego de Alvarado, fueron los actores principales y nos han presentado un resumen más extenso e interesante relacionado con el combate.

El origen del conflicto puede resumirse en las preguntas incluidas en las probanzas realizadas a participantes de la batalla, en este caso, a Bartolomé Bermúdez, quien responde:

Yten si saben \& que salidos de la provincia de Guatemala, como dicho es, toda la más parte de la tierra de guerra e si saben hacerles guerra e dársela como los de Guatemala asi a los indios de la costa del sur como a los de la tierra adentro, e si saben que toda la mas parte de esta dicha tierra vino a dar la obediencia a su Real majestad, e si saben que después de haber dado la obediencia a su majestad se rebelaron e nos mataron un español e muchos indios amigos e nos vinieron a matar estando poblados en esta dicha villa e si saben que salimos a ellos e les dimos la batalla e volvieron huyendo e se metieron en un peñol muy fuerte; diga lo que sabe." (Barón Castro, 1996:104).

Francisco de León, uno de los vecinos de San Salvador en esa época, nos proporciona otra narración: 
A la décima pregunta dijo que, lo que sabe es, desta pregunta, que cuando vinieron a poblar esta villa, los más pueblos vinieron de paz, e estando de paz el Capitán Diego de Alvarado envió un español a un pueblo e se lo mataron, con ciertos indios amigos, e toda la más parte de la tierra vino sobre el capitán e la gente de españoles a los matar, e salieron a ellos e mataron gente dellos, e les huyeron, e que esto sabe desta pregunta; e a lo del peñol, que desde a un mes poco más o menos fueron al peñol e fallaron ciertos pueblos metidos en él. (Ibid:104).

Todo indica que, una vez se estableció la villa de San Salvador en el valle de La Bermuda, una de las expediciones que fueron enviadas para pacificar el territorio cuscatleco, y probablemente para subyugar pueblos de encomienda, fue atacada por los nativos, causando la muerte de un español y de indios aliados que lo acompañaban. El resultado fue una insurrección aborigen y la consecuente necesidad de sofocarla por parte de los españoles.

Cuando el ejército español, comandado por Diego de Alvarado, llegó a Cinacantan desde San Salvador, se encontró con varios pueblos (tres o cuatro) indígenas aguerridos y agrupados sobre una formación rocosa (cerro Redondo) prácticamente inaccesible. Afrontar el peñol debió ser un verdadero reto para los españoles, ya que está rodeado de acantilados; y el lugar que presenta el acceso más fácil a la cúspide es en lado norte, donde inician los grupos de estructuras prehispánicas y donde debió estar mejor defendido. Bartolomé Bermúdez describe su participación en el ataque:

XI.- Yten si saben \&, que el dicho Diego de Alvarado, e la más parte de los españoles que estábamos con él, fuimos haciendo guerra a poner cerco al dicho peñol de cinacantlán, e si saben que el día que allegamos al dicho peñol, acometimos dos veces, e la primera nos derrocaron a pedradas e a bote de picas del peñol abajo, e si saben ser yo, el dicho Bartolomé Bermúdez, uno de los que vinieron rodando: digan lo que saben.

XII.- Yten si saben que los acometimos otra vez por otra parte doce o trece españoles, con el dicho capitán, e si saben que con galgas e piedras de mano eflechas, nos hicieron recaer, las armas rotas, por muchas partes, e heridos todos los más de los que alli estábamos, e si saben ser yo, el dicho Bartolomé Bermúdez, uno de los delanteros: a todo lo suso dicho digan lo que saben.

XIII.- Yten si saben \&, que estando como dicho es, el capitán e la más parte de nosotros heridos, e sin haber remedio de poderles ganar el peñol, e si saben que yo, el dicho Bartolomé Bermúdez, viendo el peligro en que estábamos e el gran deservicio de dios e de su Real Majestad que se seguía si no se ganase el dicho peñol, e si saben que hice una escala o argumento de madera y lo puse al pie del peñol, e si saben que como los enemigos vieron el ingenio de madera, dejaron de tirar flechas e piedras e de dar grita; digan lo que saben. (Ibid:108).

En este relato Bermúdez menciona que el día de la llegada al peñol los españoles acometieron dos veces, pero fueron repelidos en ambos intentos. En el primer ataque fueron vencidos "a pedradas e bote de picas", y que en el segundo intento fueron entre 
doce y trece españoles, acompañados por el capitán Alvarado, los que atacaron (sin duda estaban acompañados por varios indios aliados, que no se mencionan en los documentos), pero nuevamente fueron vencidos a flechazos, pedradas y con "galgas". Ante esta crítica situación, Bermúdez construyó un "argumento de madera”, y que al verlo los indios dejaron de tirar flechas. En ese momento salió uno de los señores indígenas que estaban en el peñol y les dijo a los españoles que regresaran a la villa, que ellos se pondrían al servicio de su majestad:

...luego a poco de rato salió un señor de los que dentro en el dicho peñol estaban, e dijo al capitán que nos volviésemos a la villa, que ellos querían servir, e si saben que les mandó el capitán que descendiesen del dicho peñol e que dicen la obediencia a su majestad y ellos no quisieron dejarla fuerza sino ordenar traición, como dicho es, e si saben que subimos el capitán e diez españoles e los derribamos del dicho peñol, e matamos muchos cantidades de ellos, e si saben ser yo, el dicho Bartolomé Bermúdez uno de los delanteros que con el capitán subió... (Ibid:108).

Es claro que, según el relato de Bermúdez, su aparato guerrero impresiona a los indígenas, a tal grado que dejan de lanzar proyectiles a los españoles. Al cesar el ataque temporalmente sale uno de los señores nativos para negociar, entablando conversación con Miguel Díaz Peñacorba, quien habría sido versado en la lengua náhuatl. Esto demuestra que por lo menos uno de los tres o cuatro pueblos que estaban empeñolados era pipil, por lo que esta era la etnia predominante en Cinacantan y probablemente en los asentamientos circundantes. El líder indígena les dice que regresen a la villa de San Salvador, ya que ellos se rendirán y se pondrán bajo el servicio de su majestad. Los españoles saben perfectamente que esto es un truco y deciden finalizar el combate con la ayuda del castillete móvil, llegando a la cima y haciendo gran matanza.

Esta armazón ofensiva protege a los conquistadores de las flechas, lanzas, "picas" y pedradas, logrando así llegar a la cima del peñol donde acometen contra los pipiles con armas de fuego, ballestas y espadas, matando gran cantidad de enemigos. "Algunos de los indios se despeñaron huyendo de miedo e otros mataron los españoles a espada" (Ibid:109). Es difícil determinar la forma y estructura de este aparato, pero el testigo Juan Duarte lo describe como "una burra”, para que los ballesteros llegasen hasta la cima. Francisco de León menciona que "...hizo un burro e manta para defensa e arrimarse a ella, por lo que las flechas del peñol no hiciesen daño, e que los indios desde a poco vinieron en paz, e que era opinión entre los españoles que de miedo de la defensa del burro, habian venido en paz”. Barón Castro lo describe muy bien como "una especie de castillete móvil". No es difícil imaginarse una armazón de madera cubierta con una manta de algodón que permitiera ser sostenida y manipulada por los conquistadores, quienes se protegían llevando listas sus ballestas, arcabuces y espadas. De esta forma repeliendo las pedradas, flechazos y lanzas arrojadas desde la cima mientras los atacantes se protegían debajo de la armazón al mismo tiempo que avanzaban. Bermúdez también menciona una "escala", lo que sugiere la construcción escaleras, que habrían facilitado el acceso a las partes más altas del peñol, siendo protegidos por el rudimentario pero eficiente aparato móvil. La construcción de escaleras, aparte del aparato móvil, se fundamenta en el escudo de armas concedido por Carlos V en 1537 a 
Bartolomé Bermúdez, donde aparecen dos escaleras a la par de un peñol dorado (figura 12) (Barón Castro, 1996).

Figura 12. Escudo de armas concedido por Carlos V en 1532 a Bartolomé Bermúdez. En el escudo se representa el peñón de Cinacantan al lado izquierdo y las escaleras para llegar a la cúspide del peñón al lado derecho. (Tomado de Barón Castro, (1996)

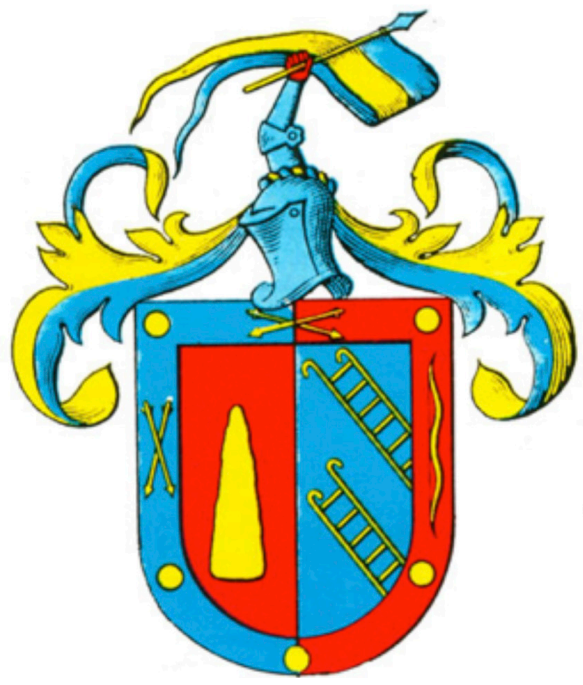

El 10 de julio de 1538, Miguel Díaz Peñacorba, el otro actor principal en la batalla expone su versión del ataque:

VII. - Si saben, vieron, oyeron decir, que andando conquistando en los términos desta villa de San Salvador, llegamos a un muy fuerte peñol de dicen Cinacantlán donde de los dos primeros acometimientos, que en términos de dos horas hicimos, fuimos heridos y despeñados la mayor parte de los españoles y que habiéndonos retirado a posar, porque ya no estábamos para la tomar a acometer, así por estar heridos y maltratados como por ser muy fuerte, yo, aventurando mi persona, me allegué solo al pie de la peña, y allí tuve plática con un Señor de los contrarios y me tomé adonde el Capitán Diego de Alvarado me quedaba esperando, y aquel Señor, y después otros salieron, y dimos orden como para concierto: entramos seis españoles desarmados en el peñol, y aunque conocimos a la traición de los enemigos, que estaban para nos matar, subimos llevando nuestras armas, secretas, siendo yo de los españoles el primero que subió, y luego subieron otros, por que por la entrada habiamos de subir uno a uno y no podíamos más, y tuvimos el peñol, hasta que del Real fuimos socorridos y fue ganado; muy gran número de enemigos muertos sin muerte de ningún español, y la tierra toda se dio al servicio de su Majestad, lo que no hiciera sin esta orden, y llegado al peñol, yo no hubiera, porque era imposible los que en la tierra estábamos, ganarlo por fuerza... (Ibid:110).

Entre los datos interesantes mencionados por Miguel Díaz Peñacorba, vale la pena resaltar la forma en que describe el ataque final al peñol. En este relato Peñacorba dice que habló con uno de los señores indígenas y que posteriormente regresó donde se encontraba esperando Diego de Alvarado. Según la versión de Bermúdez, parece que el castillete móvil impresionó a los indígenas y motivó al encuentro entre uno 
de los "señores principales" y Peñacorba. Al dar la orden de ataque, un número muy reducido de españoles penetró a la cúspide del peñol llevando "armas secretas". Según este relato, el lugar por donde ingresó Peñacorba y sus soldados es un trecho por donde había que subir uno a uno, ya que era muy angosto. El único lugar identificado que tiene estas características es el extremo noroeste del cerro Redondo. En este lugar hay una extensión rocosa en forma de alfarda angosta que facilita el acceso a la cúspide del peñol (figura 13). Este es el único lugar por donde Peñacorba y sus soldados pudieron ingresar al área defensiva e hicieron matanza entre los indios. Una vez tomado el peñol, Cinacantan fue subyugado como pueblo encomendero para que rindiera tributo; y es muy probable que este asentamiento y los pueblos que se conglomeraron para la defensa de este lugar se convirtieran en el origen del poblado de Tamanique, que apareció muchos años después, debido al reordenamiento de los poblados indígenas por parte de los españoles, esto en base a su topónimo. En 1541 el rey Carlos V concedió a Miguel Díaz de Peñacorba un escudo de armas por su valiente participación en la toma del peñón (figura 14).

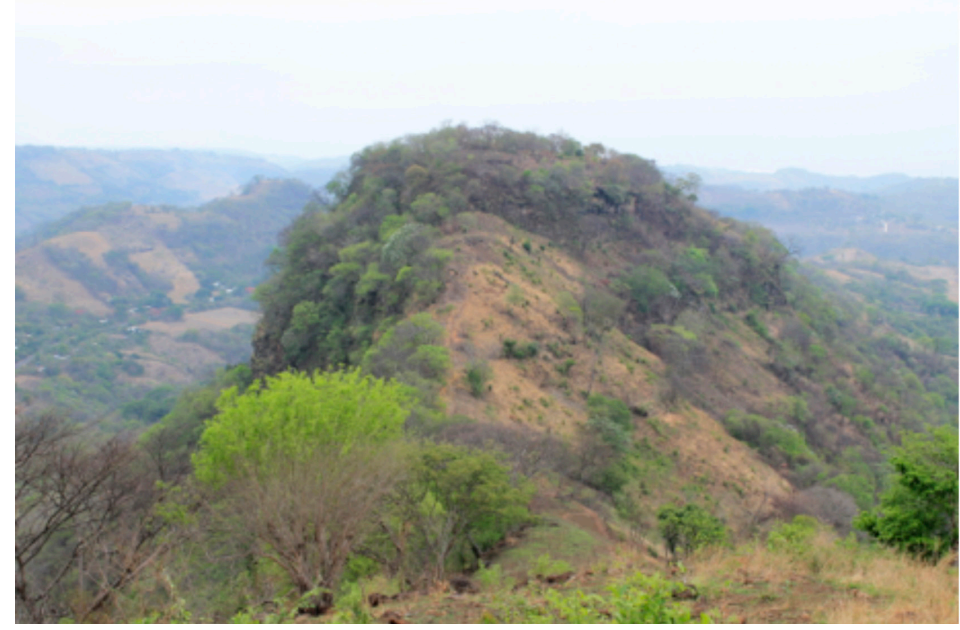

Figura 13. Acceso a la cúspide del peñón de Cinacantan

Desafortunadamente, todas las fuentes de información vienen de los españoles, por lo que probablemente nunca tendremos la versión indígena de este suceso. Los actores principales de la batalla fueron sin duda Bartolomé Bermúdez y Miguel Díaz Peñacorba, ambos bajo el mando de Diego de Alvarado; y es gracias a ellos y otros testigos presenciales que ahora tenemos conocimiento de esta importante batalla.

La toma del peñol de Cinacantan fue uno de los acontecimientos más importantes en la historia de la conquista del territorio y merece un puesto privilegiado entre los eventos que han formado la identidad salvadoreña. Tal y como lo describe Lardé y Larín: Sin duda alguna, el triunfo de las armas hispanas en el peñol de Zinacantan marcó la consolidación de la colonia en la villa de San Salvador y dejó libres a sus denodados pobladores para emprender, en nombre de Dios y de sus Majestades Católicas, la conquista de los pueblos chontales...”. 


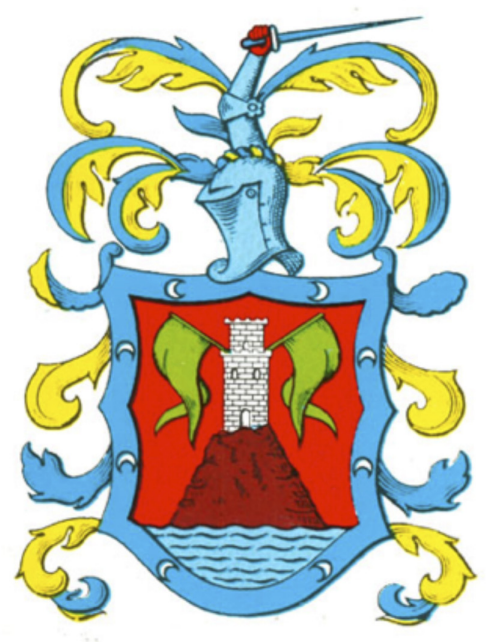

Figura 14. Escudo de armas concedido por Carlos V a Miguel Díaz Peñacorba en 1541 por su participación en la batalla de Cinacantan. Al centro, el Peñón de Cinacantan rodeado de agua. Tomado de Barón Castro (1996).

La información documental y la arqueología forman una buena idea de cómo se desarrolló este acontecimiento. Cinacantan es sin duda una de las batallas más emblemáticas y más conocidas durante la conquista de Cuscatlán. Todavía existe mucha documentación que no ha sido consultada y que complementará el rompecabezas que se ha logrado armar hasta ahora.

\section{La Relación Marroquín}

Una vez fue tomado el peñol por los españoles, los indígenas que se habían sublevado fueron subyugados y Cinacantan se convirtió en un pueblo que debió entregar tributo a los encomenderos que vivían en San Salvador. La primera vez que aparece como pueblo de encomienda es en La Relación Marroquín (Gall, 1968). Este es un documento que fue encontrado en el Archivo General de Indias (legajo 965) y paleografiado por Francis Gall. El 18 de mayo de 1532, cuatro años después de haber sido fundada la villa de San Salvador, el obispo licenciado Francisco Marroquín entrevistó a los 57 encomenderos de la villa de San Salvador, quienes le proporcionaron información sobre los pueblos encomenderos que tenía cada uno, incluyendo sus nombres, productos, número de casas y extensión de sus tierras. En algunos casos se incluía brevemente características naturales y distancias de los lugares donde se encontraban estos asentamientos. Este acto se realizó en presencia de Gómez de Alvarado, teniente gobernador y capitán de la villa, los alcaldes ordinarios, el escribano y el bachiller Antonio González Lozano, cura de la iglesia de la Trinidad en San Salvador. En La Relación Marroquín aparecen como encomenderos de Cinacantan Cristóbal de Hierros y Sancho de Figueroa. A continuación se transcribe lo que se menciona sobre Cinacantan en la declaración de Hierros:

Cristóbal de Hierros vecino de la dicha villa aviendo jurado dixo quel tiene por su rrepartimiento la mitad del pueblo de Zuacanclan (Cinacantan) e la mitad de Atequepa que ternan la dicha mitad de Zacanclan setenta y cinco casas pocas 
mas o menos a lo que cree e piensa e en la dicha mitad de Atequepa cincuenta y seis casas dos mas dos menos e que no sabe los términos que tiene el uno ni el otro porque están pueblos muy cerca dellos a dos e a tres leguas...e la dicha mitad Zuacanclan es tierra caliente...e aquel dicho Zuacanclan es tierra aspera y fragosa...e no hay donde anden (ganado) por la mucha aspereza e que no tiene sujeto ninguno e que es tierra que se da en ella bien maíz en el dicho Tequepa (sic) y en Zuacanclan muy poco...e quel dicho Zuacanclan le da de tributo sal y pescado y cuasco y alguna rropa e gallinas e otros bastimentos para su casa e miel e cera..e questa es la verdad para el juramento que hizo firmolo. (Gall, 1968).

A continuación se transcribe la declaración de Figueroa:

Sancho de Figueroa vecino en la dicha villa aviendo el juramento que en tal caso se rrequiere dixo quel tiene por rrepartimiento el otro tercio del dicho pueblo de Cojuxutepeque e la mitad de Zuacanclan...e de otros bastimentos que le da la mitad de Zuacanclan sustenta su persona e casa e cavallo dize que es tierra algo fría e caliente...e que en lo de la dicha mitad de Zuacanclan que terna en el hasta noventa casas poco mas y menos e que no tiene sujeto y esta junto a la mar e le dan algún pescado y sal y gallinas y algún cacao muy poco y algunas vezes alguna rropa blanca e que los términos que tiene serán dos leguas poco mas y menos e ques todo peñoles y entre los quales algunos vallezillos de mucha agua donde tienen sus cacaotales y que dellos y de la dicha sal y pescado biben e se da poco algodón e por ser de la dicha calidad que es cree y piensa que no podra llevar pan y vino de Castilla ni otras plantas si no fuese naranjos e limones e que tampoco se criaran bien ganados mayores e menores...e que en esta dicha mitad de Zuacanclan no ha puesto plantas ningunas asi por no las aver por lo que dicho tiene y que tampoco hay en las minas ni se espera aberlas ni con ellos coge oro asi por ellos ser muy pocos como por ellos ser muy lexos de las minas e questa es la verdad para el juramento que hizo e firmolo de su nombre. (Ibid).

Estas descripciones presentan el entorno geográfico de Cinacantan, así como los bienes que producían los nativos para entregar el tributo a los españoles. Se menciona la imposibilidad de criar ganado debido al terreno "áspero y fragoso", pero se destaca la producción de sal, pescado, gallinas, algún cacao y alguna ropa.

\section{Origen de Tamanique}

El pueblo de Tamanique es la cabecera del municipio del mismo nombre y se ubica entre las montañas de la cordillera a una altura de 600 m.s.n.m. Todavía no se tiene claro las circunstancias y acontecimientos que dieron origen a Tamanique, pero a continuación planteo una teoría. Lardé y Larín afirma que fue fundada por pueblos pocomames, para posteriormente ser conquistada por pipiles. Según este autor, este poblado ya existía al momento de la conquista española y su nombre proviene de tamani, "cosa capturada", y tepec, (españolizado tepeque), "cerro, montaña o localidad”, por lo que su etimología es "la ciudad capturada" o "cerro capturado". Posteriormente, debido a la fonética española y por el uso, Tamanitepe llegó a llamarse Tamanique (Lardé y Larín 2000). 
Todo indica que los orígenes de Tamanique pueden estar relacionados con la batalla de Cinacantan. Este sitio arqueológico, a pocos kilómetros al sur del poblado, es conocido localmente como Pueblo Viejo; y el peñón usado para la defensa indígena se llama cerro Redondo. Si el nombre Tamanique ("cerro o ciudad capturada") fue producto de este evento, entonces Tamanique como tal no existía en la época prehispánica y apareció durante la conquista española.

El poblado de Tamanique no aparece en los primeros documentos históricos relevantes, incluyendo en La Relación Marroquín. Sin embargo, se incluye Zuacanclán, que es el mismo Cinacantan. Posteriormente, en la lista de vecinos españoles de San Salvador y los pueblos indígenas que entregaban tributo en 1548 (Barón Castro, 1996) tampoco aparece Tamanique, pero nuevamente aparece Cinacantan como pueblo que entregaba tributo a Sancho de Figueroa. Es probable que Tamanique como tal fuera establecido algún tiempo después de la batalla en Cinacantan y su nombre conmemora este acontecimiento. Este asentamiento pudo haber sido el resultado de una reubicación por parte de los españoles de a los pueblos indígenas que se sublevaron. El cambio geográfico forzoso de poblados o "reordenamiento" era una práctica común durante la Conquista. Esta hipótesis amerita más estudio histórico y arqueológico.

Tamanique ya aparece en los documentos en 1740, cuando el alcalde mayor de San Salvador, don Manuel de Gálvez Corral, menciona que habían 24 indios tributarios que criaban gallinas y cultivaban maíz, algodón, cacao y bálsamo (Lardé y Larín, 2000).

"Es el último pueblo — dice Gálvez Corral-que se halla de los que llaman de la Costa del Bálsamo, cuyos caminos son montañas ásperas, que en tiempos de agua no se andan a caballo por el eminente peligro e caer en los profundísimos barrancos que hay en muy inmediatos a los caminos" (Ibid).

En 1770, Pedro Cortés y Larráz menciona que Tamanique es uno de los seis anexos que pertenecen al curato encabezado por Ateos. Los otros son: Talnique, Comayagua, Chiltiupán, Teotepeque y Jicalapa. Su población era de 32 familias con 160 personas (Cortés y Larráz, 2000).

Ingresó en 1786 en el partido de Opico y en 1807 el corregidor intendente don Antonio Gutiérrez y Ulloa hace una breve mención sobre su población indígena (Lardé y Larín 2000).

\section{Sucesos posteriores}

Como pueblo del partido de Opico, perteneció al departamento de San Salvador de 1824 (12 de junio) a 1835 (Ibid).

Como pueblo del partido de Quezaltepeque, perteneció al departamento de Cuscatlán de 1835 (22 de mayo) a 1836 (Ibid). 
Como pueblo del partido de Opico, perteneció al mismo departamento de 1836 (30 de julio) a 1842 (5 de abril), y a partir de esta última fecha, siempre como municipio del mismo partido, volvió a formar parte del municipio de San Salvador.

El 24 de noviembre de 1860 un informe municipal constata que la población contaba con 212 personas (Ibid).

\section{Conclusiones}

Poco tiempo después que los españoles establecieron el primer asentamiento estable de San Salvador en el valle de La Bermuda en 1528, ocurrió un encuentro bélico entre pipiles y europeos. En este combate murió un español y varios indios aliados, lo que desencadenó una insurrección en la que varios pueblos indígenas se agruparon en el peñón de Cinacantan, actualmente conocido como cerro Redondo. Este acto de rebeldía generó un ambiente desestabilizador y amenazante para los inmigrantes ibéricos, por lo que un contingente dirigido por Diego de Alvarado fue desplazado para subyugar a los rebeldes. Después de dos intentos fallidos, los españoles acometieron por tercera vez, logrando capturar el peñón, "haciendo gran matanza" a los naturales.

La batalla del peñón de Cinacantan, ubicado en el municipio de Tamanique, es uno de los acontecimientos más importantes en la historia de la conquista y colonización del territorio que ahora comprende El Salvador. Aunque documentos mencionan este evento e investigadores recientes han propuesto diferentes lugares para la ubicación de este sitio arqueológico, la identificación de Cinacantan como lugar donde ocurrió la batalla se logró en el año 1999, por lo que ahora es posible un estudio de arqueología histórica basado en los materiales culturales y los documentos. Ahora es posible conocer más información sobre este capítulo de nuestra historia por medio del estudio de la arquitectura, patrones de asentamiento, artefactos y demás materiales culturales presentes en este sitio, complementándolos con documentos conocidos y con los muchos que esperan ser descubiertos por los historiadores.

Considero que la batalla en Cinacantan fue el primer levantamiento indígena en Cuscatlán, ya que ocurrió poco tiempo después que los españoles establecieron la primera villa estable en el territorio. Los asentamientos españoles eran la punta de lanza en la conquista, y de estos dependía el control de los territorios. La ciudad era la llave del imperio y simbolizaba el establecimiento de un nuevo orden basado en la dominación española, formando una estructura social deseada dentro de un área geográfica de influencia, convirtiéndose la ciudad en el foco "pacificador". Aunque el conflicto entre los invasores europeos y los nativos fue un proceso que incluyó un sinnúmero de batallas que iniciaron con la "entrada" de Pedro de Alvarado en 1524, el Peñón de Cinacantan ocurrió justo después de haber fundado la villa de San Salvador en el valle de La Bermuda, llegando a ser una acción bélica simbólica y representativa para ambos grupos, conquistadores y conquistados. El hecho de que varios pueblos indígenas se "empeñolaran" y se defendieran al mismo tiempo que existía la villa de San Salvador hace que esta batalla pueda considerarse como el primer levantamiento indígena en el territorio de Cuscatlán. 
Sin duda alguna, el triunfo de las armas hispanas en el peñol de Zinacantan marcó la consolidación de la colonia en la villa de San Salvador y dejó libres a sus denodados pobladores para emprender, en nombre de Dios y de sus Majestades Católicas, la conquista de los pueblos chontales... (Lardé y Larín, 2000).

\section{Referencias bibliográficas}

Amaroli, Paul. Linderos y geografía económica de Cuscatlán, provincia pipil del territorio de El Salvador. En Mesoamérica, número especial: El Salvador, pp. 41-70. CIRMA, Antigua Guatemala, Guatemala. 1991.

Barón Castro, Rodolfo. Reseña Histórica de la Villa de San Salvador. Dirección de Publicaciones e Impresos. Consejo Nacional para la Cultura y el Arte, Concultura. 1996

Cobos, Rafael. Síntesis de la Arqueología de El Salvador. Colección Antropología e Historia. Concultura, El Salvador. 1994.

Erquicia Cruz, José Heriberto. Proyecto de Registro y Reconocimiento de Sitios Arqueológicos Históricos de El Salvador. Fase I. Universidad Tecnológica de El Salvador, Escuela de Antropología, Facultad de Ciencias Sociales. San Salvador, El Salvador. 2008.

Escamilla, Marlon. La Costa del Bálsamo durante el postclásico temprano (900-1200 d.C): una aproximación al paisaje cultural nahua-pipil. En La Universidad. Número 14-15. AbrilSeptiembre, 2011. Universidad de El Salvador. 2011.

Informe arqueológico de los petrograbados del sitio Piedra Herrada, Comasagua. Informe inédito en el Departamento de Arqueología, Secretaría de Cultura. 1999.

Fowler Jr., William. El Salvador Antiguas Civilizaciones. Banco Agrícola Comercial. San Salvador, El Salvador. 1995.

The Cultural Evolution of Ancient Nahua Civilizations. The Pipil-Nicarao of Central America. University of Oklahoma Press: Norman and London. 1989.

Fowler, William Jr;; Amaroli, Paul y Arroyo, Bárbara. Informe Preliminar del Proyecto Izalco. Temporada 1988. Informe inédito. Preparado para la Administración de Patrimonio Cultural, El Salvador, San San Salvador. 1989.

Gall, Francis. El Licenciado Francisco Marroquín y una descripción de El Salvador, año de 1532. Anales de la Sociedad de Geografía e Historia de Guatemala. Tomo XLI (Abril-Dic., 1968), no. 2 y 4 . Guatemala. 1968.

Gallardo, Roberto. "El origen de la identidad salvadoreña. Etnicidad en la antigua villa de San Salvador". En revista Koot, Museo Universitario de Antropología, Año 1, No.1 . pp. 101-114. 2010.

"El Sitio Arqueológico Zincantan Pueblo Viejo". En Fiestas Patronales del Municipio de Tamanique. Revista de la Alcaldía Municipal de Tamanique en conmemoración de las fiestas patronales 2005. 2005.

Gierloff-Emden, H. G. La costa de El Salvador. Ministerio de Educación, Dirección de 
Publicaciones. San Salvador, El Salvador. 1976.

Hamilton, Connard. Zinacantan Mapping Proyect. Documento inédito depositado en la Dirección de Arqueología del Museo Nacional de Antropología Dr. David J. Guzmán, San Salvador. 2002.

Lardé y Larín, Jorge. El Salvador: Historia de sus pueblos villas y ciudades. Dirección de Publicaciones e Impresos. Consejo Nacional para la Cultura y el Arte, Concultura. 2000.

El Salvador: Descubrimiento, Conquista y Colonización. Dirección de Publicaciones e Impresos, Consejo Nacional para la Cultura y el Arte, Concultura. 2000.

Lexa, Jaroslav, Jiri Sebesta, José Alexander Chávez, Walter Hernández, Zoltan Pecskay “Geology and volcanic evolution in the southern part of the San Salvador Metropolitan Area". En Journal of Geosciences, 56 (2011), 105-140. 2011.

Méndez, Miriam. "Vida entre montañas". En El Salvador Investiga No.9. Proyección de Investigaciones. Centro de Gobierno, Concultura. 2007.

Revene, Zachary. "Los balsameros de Atiluya". En El Salvador Investiga. Proyección de Investigaciones. Centro de Gobierno, Concultura, El Salvador. 2007.

Williams H, Meyer Abich. "Volcanism in the southern part of El Salvador with particular reference to the Collapsed basins of Coatepeque and Ilopango". Universidad de California. Publ Geol Sci 32:1-64. 1955. 
